\title{
Can a biobank network and supporting infrastructure enhance Ireland's ability to attract pharmaceutical research and development and clinical trial opportunities? A pilot survey
}

\author{
This article was published in the following Dove Press journal: \\ Journal of Biorepository Science for Applied Medicine \\ 21 June 2016 \\ Number of times this article has been viewed
}

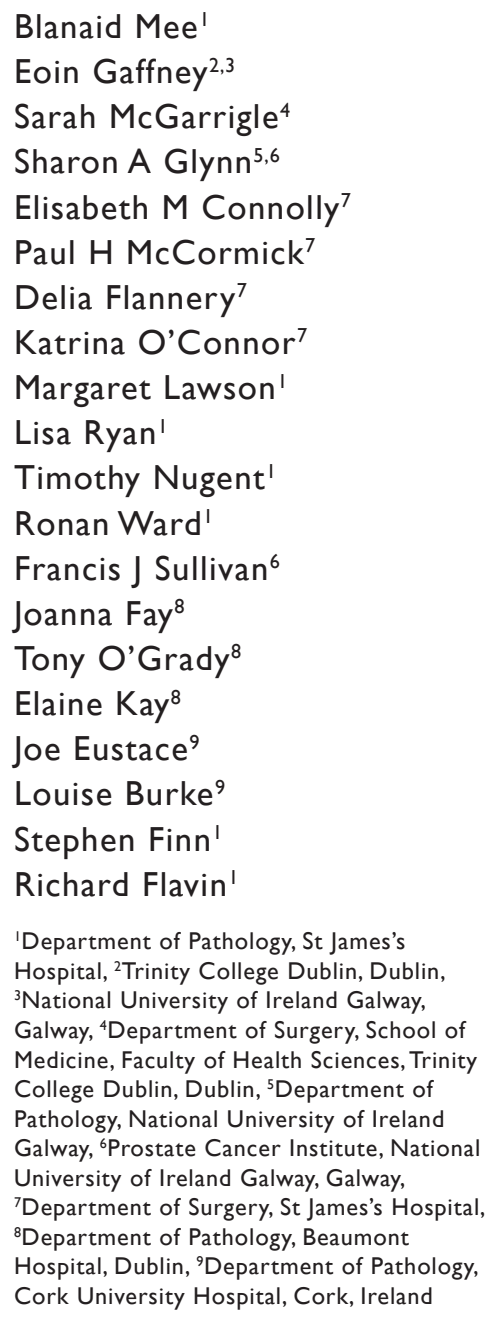

Correspondence: Blanaid Mee Biobank, Department of Pathology, Central Pathology Laboratory, St James's Hospital, James's Street, Dublin 8, Ireland Email bmee@stjames.ie

\begin{abstract}
Ireland has an established reputation in specialized global pharmaceutical manufacturing. However, simple high-volume manufacturing will not sustain the Irish pharmaceutical industry, and government agencies recommend a greater focus on innovation and research and development (R\&D). Biobank Ireland Trust sought the views of the Irish pharmaceutical industry on the potential benefits of a national biobank network (NBN), national biobank web portal (NBWP), and center for translational molecular oncologic pathology (CTOP). Questionnaires were sent to 19 companies and eleven responded. Questionnaire A was completed by six companies presently engaged in $\mathrm{R} \& \mathrm{D}$ in Ireland - three pharmaceutical companies, two spin outs, and one contract research organization. Six of six respondents reported that: a NBN would benefit their company; the development of a NBWP was important; and finally, they forecast that the requirement for biobanked material would continue to increase. While three of six predicted that a NBN would facilitate an expansion of current $R \& D$ activities. The relative importance of accessing biobanked material and data varied. An associated NBWP was considered essential to enable researchers to rapidly determine the content of the NBN for research, including preclinical studies. Individual companies had requirements for biobanked material from a wide variety of cancer sites, sample types, and sample derivatives. Questionnaire B was completed by five pharmaceutical companies currently not engaged in R\&D in Ireland. Four of five reported that a CTOP would benefit their company. All five stated that a CTOP could cultivate industry-academic collaborations. All five also determined that NBN-NBWP-CTOP infrastructure would assist in promoting Ireland as an R\&D center. Finally, four of five indicated that an NBN would make Ireland more competitive for new clinical trials. This pilot survey suggests that an NBN with associated infrastructure would greatly facilitate research conducted by the pharmaceutical sector in Ireland.
\end{abstract}

Keywords: pharmaceutical industry, Irish biobanks, NBN, CTOP, NBWP, biobanked material

\section{Introduction}

Ireland, as the location of choice for 8 of the top 10 pharmaceutical companies, and producer of 5 top 20 medicines, is an important manufacturing base for the world's pharmaceutical industry. ${ }^{1-10}$ However, it is now recognized that simple high-volume manufacturing alone will not sustain the long-term future of pharmaceutical companies in Ireland. Government agencies recommend focusing on innovation and research and development (R\&D) and developing formal processes to exploit the complementary 
expertise in academia and industry. ${ }^{11}$ Globally, fiscal consolidation, spiraling R\&D costs, declining research pipelines, and the decline of blockbusters, ie drugs which generate in excess of 1 billion dollars per annum, are challenges currently facing the industry. ${ }^{1-12}$ Ireland also faces specific challenges: it is one of the most costly countries in the Euro zone to do business, several drugs, manufactured in Ireland, went off patent in quick succession, and there is a need for a better mechanism for the integration of novel biomarkers into treatment plans for oncology patients. ${ }^{9-12}$ Increasingly, patients receive specific targeted therapies for cancer, and anecdotal evidence would suggest that cohesive structures do not exist to expedite the integration of novel and emerging biomarker tests into the Irish health care system.

Traditionally, Irish biobanks have been utilized by researchers in academic institutions. Industry-academic collaborations have been limited, possibly attributable to a person-dependent culture. ${ }^{12}$ The degree to which the industry has utilized biobanks is difficult to establish. Without a national catalog of biobanked material, it is also difficult to pinpoint the number of samples, at various institutions, which could potentially (with the correct consent) be made available to industry. Biobank Ireland Trust (BIT) was established to promote the development of a National Biobank Network (NBN). The network, which commenced in 2008, aims to deliver benefits for patients, researchers, industry, and the economy. ${ }^{13,14}$ BIT engages with stakeholders, including patient advocate groups, who are positive about industry accessing their donated biobanked material (blood, tissue, etc), because of the hope of new and improved treatments. BIT's network, which is under development, could also act as an interface between industry and academia, to assist in fostering collaborations.

It is important that the network can facilitate both academic and industrial researchers, providing all projects are 1) ethically approved and 2) satisfy the criteria laid down in the Sample Access Policy. ${ }^{14}$ Therefore, BIT sought to obtain an overview of R\&D currently being undertaken by the Irish pharmaceutical industry, to identify industryspecific biobank requirements, and to determine whether a national biobank web portal (NBWP) or searchable online catalog of biobanked material and center for translational molecular oncologic pathology (CTOP) would add value to the network.

\section{Methods}

In June 2013, BIT hosted a meeting with representatives from industry. There were four objectives: 1) to enable BIT to gain a more comprehensive overview of the landscape of $R \& D$ within the Irish pharmaceutical industry, 2) to identify the biobanking requirements of industry in the next $1-5$ years, 3) to increase visibility and keep industry abreast of recent NBN developments, and 4) to identify differences, if any, that exist between the biobanking needs of industry and academia.

The attendees included representatives from global pharmaceutical companies with affiliates in Ireland, one contract research organization and two spin-out companies, established to exploit intellectual property generated in higher education institutes. ${ }^{15,16}$

Although the generic requirements of industry were identified, the specific requirements of individual companies were not determined, possibly attributable to a reluctance to discuss the exact nature of future research in front of competitors. Following internal discussion, it was decided that follow-up questionnaires emailed privately to each company representative might prove more effective at determining the precise requirements of industry for a NBN and related infrastructure.

Two questionnaires were generated and submitted to 19 companies. Questionnaire A was developed for companies conducting R\&D in Ireland, while Questionnaire B was for companies without a research footprint (Figures 1 and 2). Questionnaire A asked whether an NBN would benefit an individual company and cultivate further R\&D opportunities, to evaluate the development of NBWP and to outline present and future biobank material requirements. Questionnaire B sought to determine whether a NBWP and CTOP linked to a NBN have the capacity to benefit industry, cultivate future industry-academic collaborations, and assist in promoting Ireland as a viable R\&D center. Questionnaires were based on BIT's engagement with industry and feedback from the June 2013 meeting. Respondents' names and companies were pseudoanonymized to protect commercially sensitive information. Fionnuala Gibbons (Molecular Medicine Ireland) was instrumental in making BIT aware of a number of small to medium indigenous enterprises.

\section{Results}

Of the 19 companies, eleven (58\%) completed the questionnaires. Replies were not received from the other companies, despite follow-up emails and phone calls.

\section{Questionnaire A}

Questionnaire A was completed by six companies presently engaged in R\&D in Ireland - three pharmaceutical companies, two spin outs, and one contract research organization. 

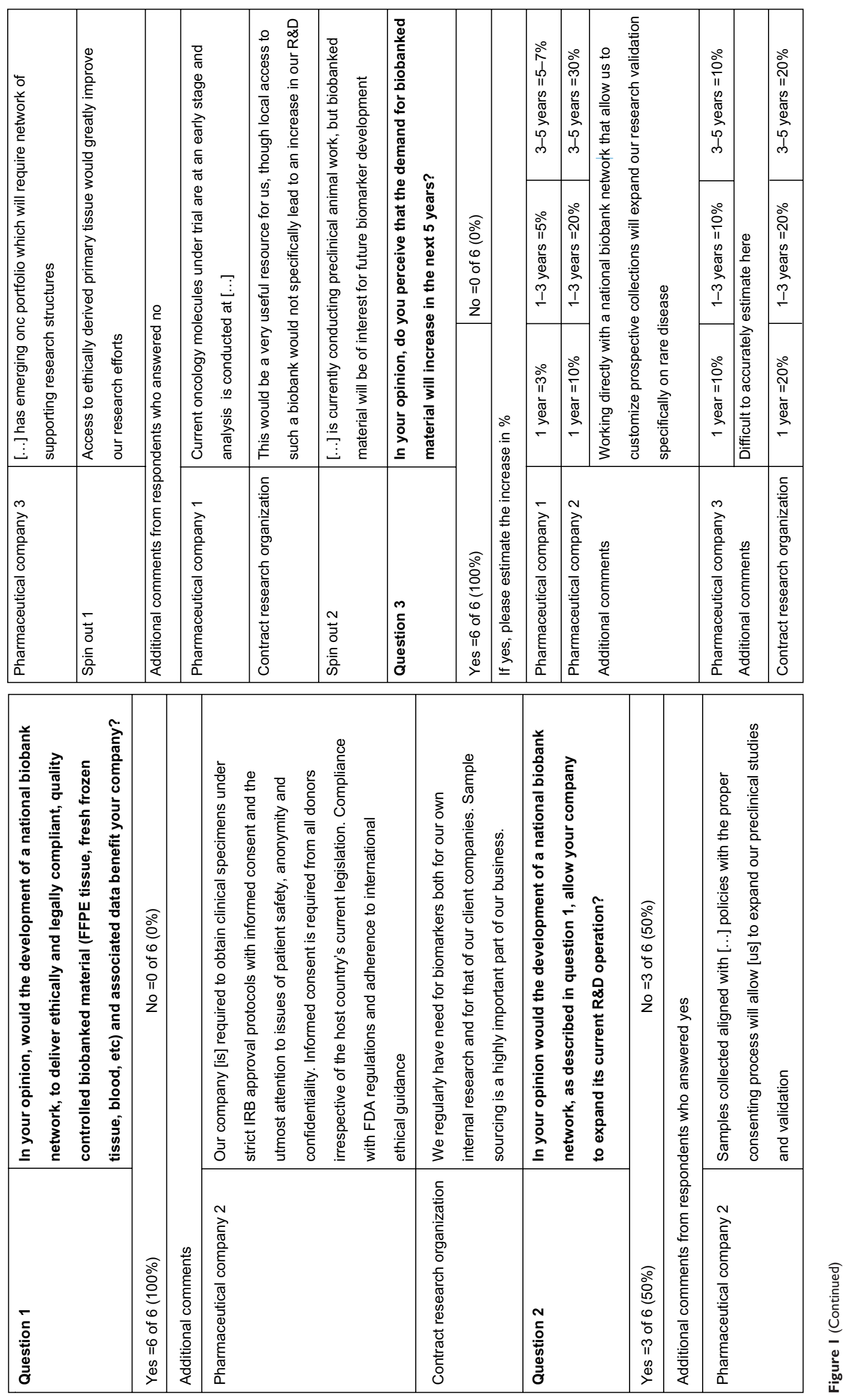

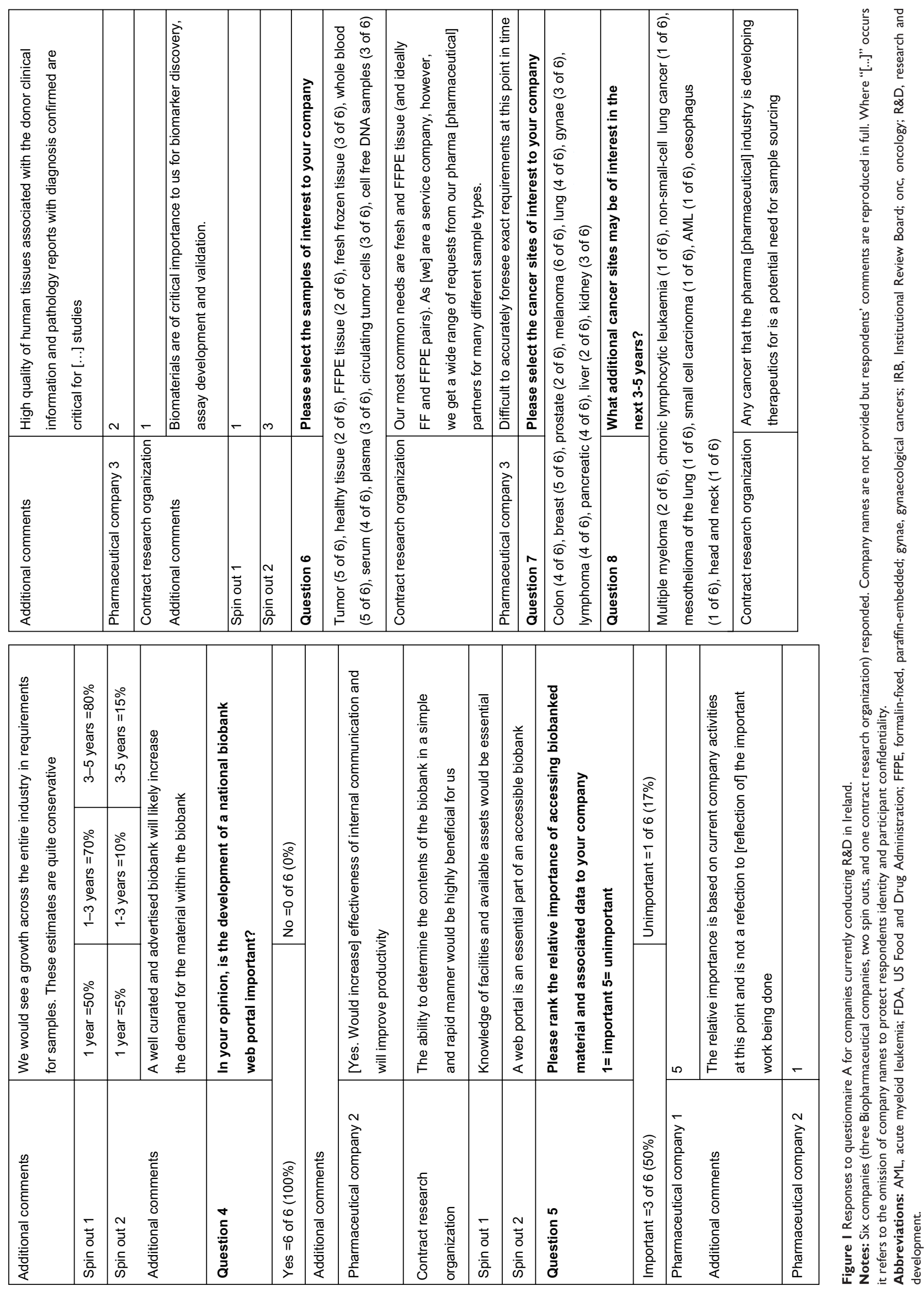

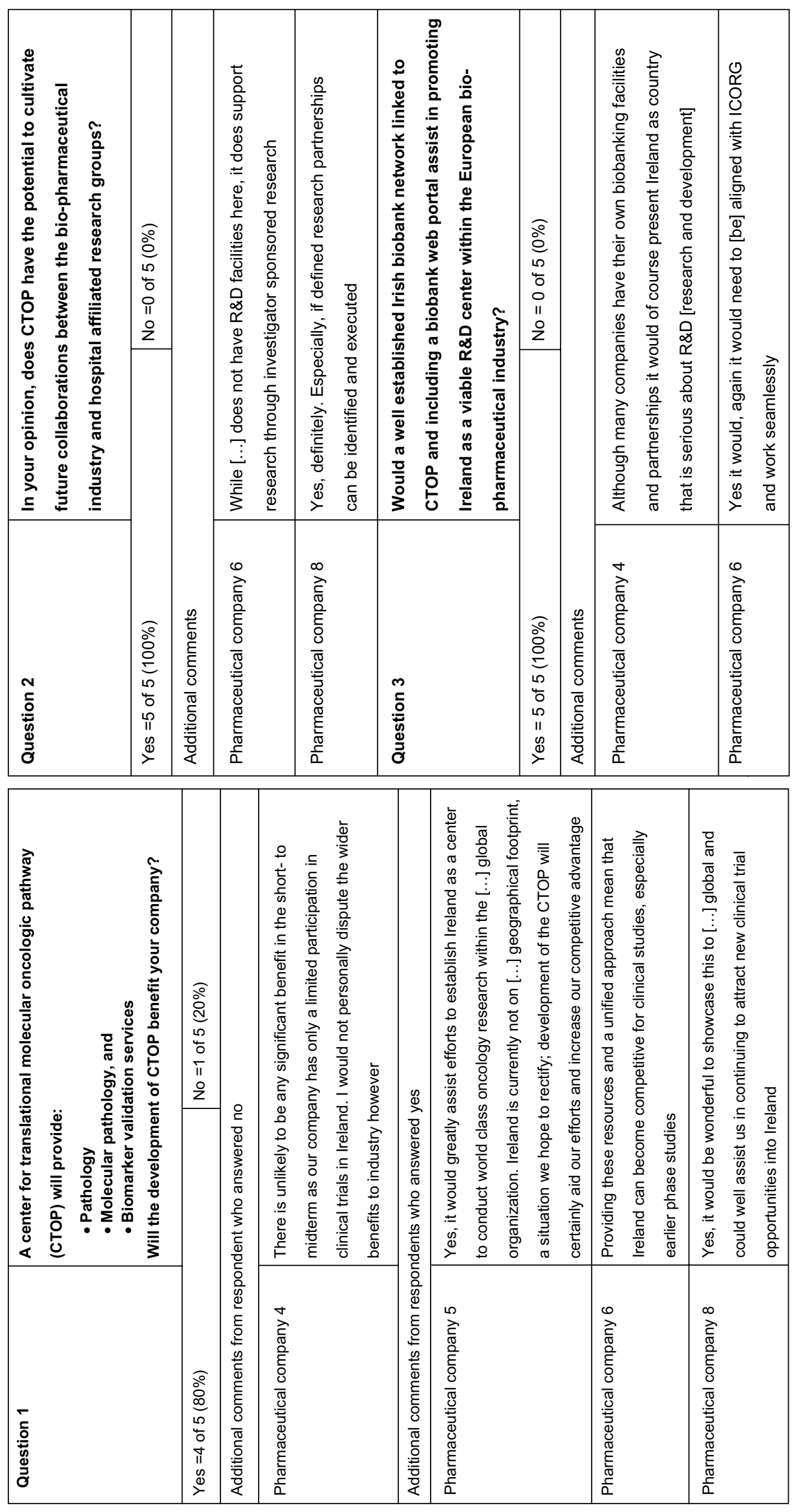

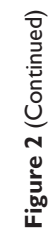




\begin{tabular}{|c|c|c|c|c|c|c|c|c|}
\hline 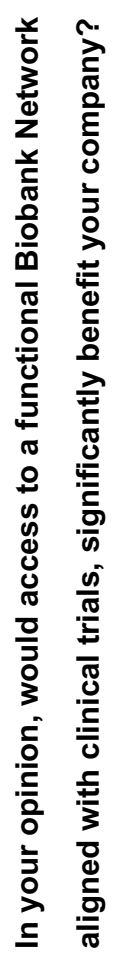 & 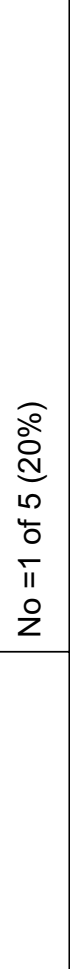 & 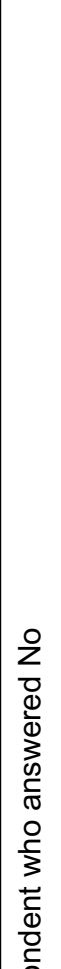 & 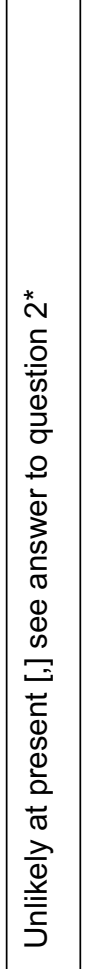 & 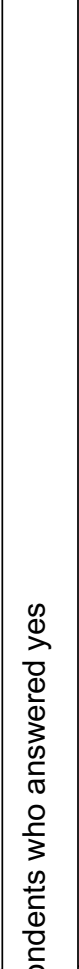 & 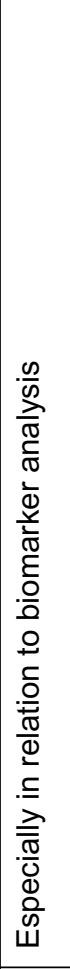 & 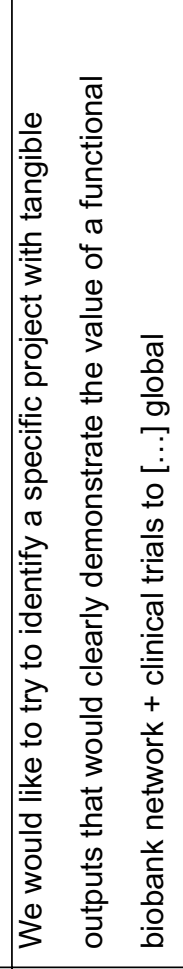 & 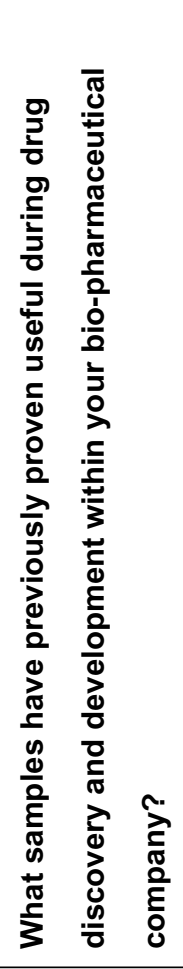 & 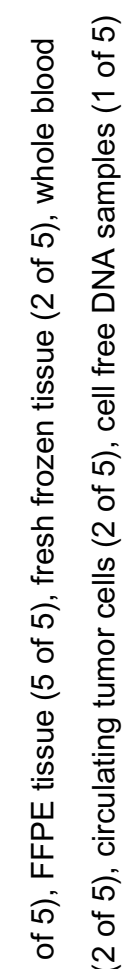 \\
\hline 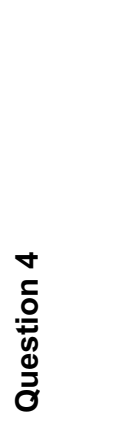 & 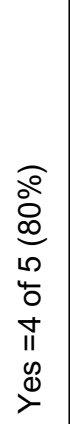 & 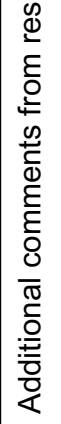 & 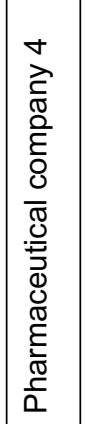 & 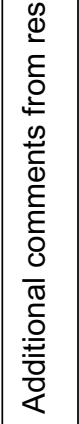 & 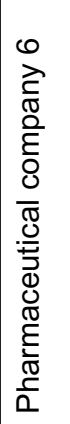 & 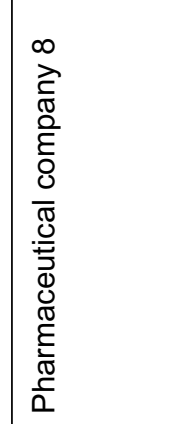 & 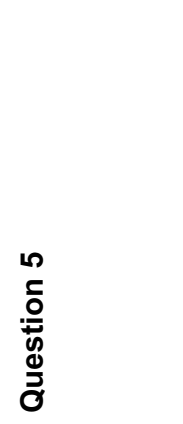 & 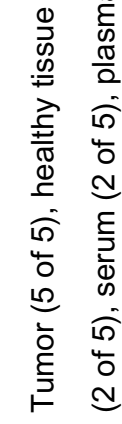 \\
\hline
\end{tabular}

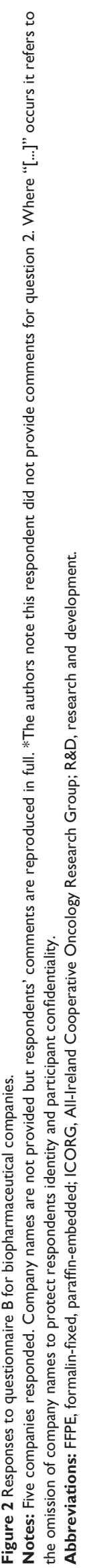


Six of six respondents reported that: a NBN would benefit their company; the development of a NBWP was important; and finally, they forecast that the requirement for biobanked material would continue to increase. While three of six predicted that a NBN would facilitate an expansion of current R\&D activities. The relative importance of accessing biobanked material and data varied. An associated NBWP was considered essential to enable researchers to rapidly determine the content of the NBN for research, including preclinical studies. Individual companies had requirements for biobanked material from a wide variety of cancer sites, sample types, and sample derivatives. Results and respondent's comments are presented in Figure 1.

\section{Questionnaire B}

Questionnaire B was completed by five pharmaceutical companies currently not engaged in R\&D in Ireland. Four of five reported that a CTOP would benefit their company. All five stated that a CTOP could cultivate industry-academic collaborations. All five also determined that NBN-NBWPCTOP infrastructure would assist in promoting Ireland as a R\&D center. Finally, four of five indicated that an NBN would make Ireland more competitive for new clinical trials.

\section{Discussion}

In this pilot survey of the Irish pharmaceutical sector, companies, whether engaged in R\&D (Questionnaire A) or not (Questionnaire B), stated that NBN-NBWP-CTOP would benefit them. The companies predicted an increase in demand for biobanked material in the ensuing 5 years. NBN-NBWP-CTOP infrastructure could also assist in attracting new clinical trials, in promoting Ireland as a viable R\&D center, and in cultivating novel industry-academic collaborations. Results cannot be compared with those of two previous studies because Ireland is not yet a member of Biobanking and Biomolecular Resources Research Infrastructure, and awaits both biobank legislation and a governing authority, as in the United Kingdom. ${ }^{17-19}$ In contrast to

Table I Comparison of industry and academia requirements

\begin{tabular}{ll}
\hline Industry & Academia \\
\hline Broad spectrum research - companies & Narrow research focus - the \\
typically investigating between four and & $\begin{array}{l}\text { vast majority of researchers } \\
\text { investigating one (47.7\%) or } \\
\text { I5 cancer sites simultaneously }\end{array}$ \\
Highly variable sample types utilized & $\begin{array}{l}\text { Highly specific sample types } \\
\text { utilized }\end{array}$ \\
Short timelines & \\
\hline
\end{tabular}

industry, academic researchers, based on an unpublished survey of 44 researchers attending the Irish Society for Cancer Research Meeting in 2011, investigate only one or two cancer sites and require fewer and less varied sample types or derivatives (Table 1).

The NBN represents a mechanism for delivering biobanked material from a variety of cancer sites, sample types, and numbers required by industry. ${ }^{20,21}$ For academics, the NBN represents a mechanism to provide the high volume of biobanked material required to establish robust genetic associations and to facilitate inclusion on pan-European and/or international studies. ${ }^{20,21}$ The NBWP, currently under development with SuprTecBox Ltd, will allow researchers to explore biobanked material within the NBN and to customize investigations accordingly. An NBN could also reduce the use of international tissue procurement organizations by Irish companies, and thereby help to sustain the NBN and related infrastructures.

Large pharmaceutical companies are increasingly partnering with smaller entities to bolster their waning pipelines. ${ }^{11}$ Forty percent of pipeline products are now sourced externally, as purchasing promising candidates is more cost-effective. ${ }^{11,22}$ The dearth of novel pipeline therapeutics provides small indigenous Irish companies, higher education institutes, and spin outs, currently developing novel molecular entities, with an opportunity to broker high value intellectual property licensing and/or partnering models. ${ }^{23-25}$ By engaging later in the R\&D process, pharmaceutical companies can apply stringent criteria to minimize or reduce the risk of choosing a dead end pharmaceutical product. This should benefit Ireland's knowledge economy and promote Ireland as a viable R\&D center. ${ }^{11,23-25}$ Ultimately, to attract greater pharmaceutical R\&D investment, Ireland must demonstrate that 1) cohesive biobanking, clinical trial, and research infrastructures are in situ, 2) excellent collaboration exists between academia and industry, 3) formal intellectual property and licensing agreements are in place between various higher education institutes and the pharmaceutical industry, and 4) that there is a national capacity to commercialize research.

\section{Conclusion}

The results of this pilot survey suggest that the benefits of an Irish NBN could be far-reaching and complement the numerous recommendations proffered by various government reports and strategy documents on the Irish pharmaceutical sector. ${ }^{11,15,16,23-25}$ A properly resourced NBN-NBWP-CTOP infrastructure has the potential to streamline and transform how Irish researchers access biobanked material and associated 
data. The need for a CTOP facility is emphasized by the drive to integrate biomarker discovery and validation into oncology clinical trials, via the provision of biobanked material. An NBN and supporting infrastructure has the capacity to enable Irish affiliates of global pharmaceutical companies to compete more effectively within their parent organizations, within Europe, and internationally, and to secure additional clinical trial opportunities and R\&D investment.

\section{Disclosure}

The authors report no conflicts of interest in this work.

\section{References}

1. Fitzgerald J. The effect on major national accounting aggregates of the ending of pharmaceutical patents. ESRI research note. Available from: https://www.esri.ie/publications/the-effect-on-major-nationalaccounting-aggregates-of-the-ending-of-pharmaceutical-patents/ Accessed April 2, 2016.

2. Bringing health and growth to Ireland. 2014. Available from: http:// www.ipha.ie/alist/publications.aspx?article $=987 \mathrm{ba} 9 \mathrm{cc}-\mathrm{b} 8 \mathrm{f} 6-4 \mathrm{f} 08-900 \mathrm{c}-$ 3fce968ac81d. Accessed April 4, 2016.

3. Pharmaceutical healthcare facts and figures. 2012. Available from: http:// www.ipha.ie/alist/healthcare-facts-and-figures.aspx. Accessed April 4, 2016.

4. Pharmaceutical healthcare facts and figures. 2010. Available from: http:// www.ipha.ie/alist/healthcare-facts-and-figures.aspx. Accessed April 4, 2016.

5. Pharmaceutical healthcare facts and figures. 2009. Available from: http:// www.ipha.ie/alist/healthcare-facts-and-figures.aspx. Accessed April 4, 2016.

6. Pharmaceutical healthcare facts and figures. 2008. Available from: http:// www.ipha.ie/alist/healthcare-facts-and-figures.aspx. Accessed April 4, 2016.

7. Matt M. Worst effects of patent cliff seem to be behind us. Irish Pharma Chem - Industry Buyers Guide. Dublin, Ireland: Tara Publishing Ltd; 2015:7-9.

8. The pharmaceutical industry - working for well-being. 2005. Available from: http://www.ipha.ie/alist/industry-reports.aspx. Accessed April 4, 2016.

9. The impact of the patent cliff on pharma-chem output in Ireland. Department of Finance. 2013. Available from: http://www.finance.gov.ie/sites/ default/files/The $\% 20$ Impact $\% 20$ of $\% 20$ the $\% 20$ Patent $\% 20$ Cliff $\% 20$ on $\% 20$ Pharma-Chem\%20Output $\% 20$ in\%20Ireland.pdf. Accessed April 4, 2016.

10. Health (Pricing and Supply of Medical Goods) Act 2013. Available from: http://www.irishstatutebook.ie/pdf/2013/en.act.2013.0014.pdf. Accessed April 4, 2016.
11. Future skills requirements of the biopharma-pharmachem sector. 2010. Available from: http://edepositireland.ie/handle/2262/69834. Accessed April 4, 2016.

12. O'Connell D. How International BioPharma views Ireland. Poster presented at: IPPOSI National Strategic Summit on Clinical Research, November 27, 2009, Dublin, Ireland.

13. Mee BC, Carroll P, Donatello S, et al. Maintaining breast cancer specimen integrity and individual or simultaneous extraction of quality DNA, RNA, and proteins from allprotect-stabilized and nonstabilized tissue samples. Biopreserv Biobank. 2011;9:389-398.

14. Mee B, Gaffney E, Glynn SA, et al. Development and progress of Ireland's biobank network: ethical, legal, and social implications (ELSI), standardized documentation, sample and data release, and international perspective. Biopreserv Biobank. 2013;11:3-11.

15. Inventions and innovations - the positive impact of ideas from research on Irish industry and society. 2012. Available from: http:// www.enterprise-ireland.com/EI_Corporate/en/Publications/ReportsPublished-Strategies/Inventions-and-Innovations.pdf. Accessed April 4, 2016.

16. Putting public research to work for Ireland. 2012. Department of Jobs, Enterprise and Innovations. Available from: http://www.knowledgetransferireland.com/About_KTI/Knowledge-Transfer-Framework/. Accessed April 4, 2016.

17. Van Ommen GB, Törnwall O, Bréchot C, et al. BBMRI-ERIC as a resource for pharmaceutical and life science industries: the development of biobank-based expert centres. Eur J Hum Genet. 2014;23:893-900.

18. Biobanks need pharma [editorial]. Nature. 2009;461(7263):488.

19. Womack C, Mager SR. Human biological sample biobanking to support tissue biomarkers in pharmaceutical research and development. Methods. 2014;70:3-11.

20. Heijmans BT, Mill J. Commentary: the seven plagues of epigenetic epidemiology. Int J Epidemiol. 2012;41:74-78.

21. Fizazi K, Abrahamsson PA, Ahlgren G, et al. Achievements and perspectives in prostate cancer phase 3 trials from genitourinary research groups in Europe: introducing the prostate cancer consortium in Europe. Eur Urol. 2015;67(5):904-912.

22. Byrne G. Virtual Pharma-Challenges of Drug Development. Business Plus Magazine. December 14-16, 2014.

23. Strategy in action. 2012. Available from: http://www.interphex.com/_nov adocuments/71775?v=635580600357000000. Accessed April 4, 2016.

24. Ireland: the location of choice for scientific investment. 2011. Available from: http://www.idaireland.com/newsroom/ireland-a-favoured-fdi. Accessed April 4, 2016.

25. Pharmachemical Ireland strategy - innovation and excellence. 2010. Available from: http://www.ipha.ie/alist/industry-reports. asp ? page $=1 \&$ article $=63 \mathrm{~d} 38289-882 \mathrm{c}-4576-8 \mathrm{fbf}-9 \mathrm{f} 23 \mathrm{f} 37425 \mathrm{bd}$. Accessed April 4, 2016.
Journal of Biorepository Science for Applied Medicine

\section{Publish your work in this journal} Journal of Biorepository Science for Applied Medicine is an international, peer-reviewed,
open access journal that focuses on new developments and advances in the emerging and evolving field of biorepository science. This includes biospecimen procurement, processing, preservation, and banking for application to applied medicine. The Journal invites submission of manuscripts which address these aspects in addition to systems logic, clinical throughput and ethical issues pertaining to application of biorepositories

Submit your manuscript here: http://www.dovepress.com/journal-of-biorepository-science-for-applied-medicine-journal

\section{Dovepress}

and their affects on clinical medicine. The journal is characterized by the rapid reporting of reviews, original research, methodologies, technologies and analytics in this subject area. The manuscript management system is completely online and includes a very quick and fair peer-review system, which is all easy to use. Visit http://www.dovepress. com/testimonials.php to read real quotes from published authors. 